\title{
Multiscale Drivers of Water Chemistry of Boreal Lakes and Streams
}

\author{
Sonja Stendera $\cdot$ Richard K. Johnson
}

Received: 21 June 2005/Accepted: 17 February 2006

(C) Springer Science+Business Media, Inc. 2006

\begin{abstract}
The variability in surface water chemistry within and between aquatic ecosystems is regulated by many factors operating at several spatial and temporal scales. The importance of geographic, regional-, and localscale factors as drivers of the natural variability of three water chemistry variables representing buffering capacity and the importance of weathering (acid neutralizing capacity, ANC), nutrient concentration (total phosphorus, $\mathrm{TP}$ ), and importance of allochthonous inputs (total organic carbon, TOC) were studied in boreal streams and lakes using a method of variance decomposition. Partial redundancy analysis (pRDA) of ANC, TP, and TOC and 38 environmental variables in 361 lakes and 390 streams showed the importance of the interaction between geographic position and regional-scale variables. Geographic position and regional-scale factors combined explained $15.3 \%$ (streams) and $10.6 \%$ (lakes) of the variation in ANC, TP, and TOC. The unique variance explained by geographic, regional, and local-scale variables alone was $<10 \%$. The largest amount of variance was explained by the pure effect of regional-scale variables $(9.9 \%$ for streams and $7.8 \%$ for lakes), followed by local-scale variables $(2.9 \%$ and $5.8 \%)$ and geographic position $(1.8 \%$ and $3.7 \%$ ). The combined effect of geographic position, regional-, and local-scale variables accounted for between $30.3 \%$ (lakes) and 39.9\% (streams) of the variance in surface water chemistry. These findings lend support to the
\end{abstract}

S. Stendera $(\square) \cdot$ R. K. Johnson

Department of Environmental Assessment

Swedish University of Agriculture

P. O. Box 7050, SE-750 07 Uppsala, Sweden

E-mail: Sonja.Stendera@ma.slu.se conjecture that lakes and streams are intimately linked to their catchments and have important implications regarding conservation and restoration (management) endeavors.

Keywords ANC $\cdot$ Total phosphorus $\cdot$ TOC $\cdot$ Partial RDA · Variation partitioning - Spatial scale $\cdot$ Lentic Lotic $\cdot$ Geographic position

\section{Introduction}

Surface water chemistry is regulated by a complex suite of processes and mechanisms operating at varying spatial and temporal scales. Early work by lake ecologists focused on the importance of geographic position as a strong predictor of lake water chemistry. For instance, in the early 1900s, Thienemann (1925) and Naumann (1932) developed lake trophic classification schemes that basically recognized differences between lowland, nutrient rich (eutrophic) and alpine, nutrient poor (oligotrophic) ecosystems. Although lake ecologists were early to appreciate the importance of adjacent land type on lake-water chemistry, stream ecologists have addressed the terrestrial-aquatic linkage concept more formally, with streams being regarded as "open systems that are intimately linked with their surrounding landscapes" (e.g., Hynes 1975). However, lake ecologists have recently revisited the landscape position hypothesis and formalized paradigms that recognize more explicitly the importance of landscape position and its significance for describing among-lake variance (e.g., Kratz and others 1997; Soranno and others 1999; Riera and others 2000).

The surrounding landscape (catchment) with its distinct geology, hydrology, and climate clearly influences the physico-chemical features of a specific water body (e.g., 
Omernik and others 1981; Osborne and Wiley 1988; Allan 1995; Kratz and others 1997; Soranno and others 1999; Riera and others 2000), and several studies have highlighted the links between surface water chemistry and catchment characteristics, particularly in relation to sensitivity to nutrient enrichment and acidification (Vollenweider 1975; Sverdrup and others 1992; Hornung and others 1995). Indeed, water chemistry, both within and among lakes or streams, is considered to be driven by factors acting on both regional and local scales. Regional factors such as climate, geology and weathering are interrelated with other factors such as soil type and land cover/use, whereas local factors, like the input and retention of organic matter, are related to the vegetation type and topographical relief. Hence, a priori, a close linkage is expected between regional- and local-scale factors. Geographic proximity alone is, however, often not sufficient to predict the physical and chemical characteristics of individual streams or lakes, as differences in external processes such as stream hydrology or lake morphometry and water retention time as well as internal processes such as nutrient cycling, and strengths of interactions with the surrounding landscape may singly or in concert confound the importance of regional-scale factors.

Although a number of studies have addressed the importance of land use/type on surface water chemistry, few studies have simultaneously focused on the importance of local and regional factors as determinants of surface water chemistry, and fewer still have addressed the similarities and differences of lake and stream ecosystems. To our knowledge, only one study (Essington and Carpenter 2000) has simultaneously studied the response of stream and lake ecosystems. These authors showed that streams and lakes were surprisingly similar in nutrient cycling, in particular when adjustments were made for water residence time. By concurrently studying stream and lake ecosystems, we hope to better our understanding of the processes and mechanisms that drive surface water chemistry in these different, but certainly not ecologically isolated ecosystems.

We hypothesize that both streams and lakes are strongly linked to the surrounding landscape, and that spatial variation in surface water chemistry is regulated by nonmutually exclusive factors acting on various hierarchical scales depending on landscape type and/or geographic position. Here, we study the effect of regional and local-scale factors on three commonly measured water chemical variables. Acid neutralizing capacity (ANC) was selected to indicate the effect that catchment geology and weathering might have on buffering capacity. Total phosphorus (TP) was selected for its key role in driving ecosystem productivity and because it is biologically active (i.e., is expected to decrease along, e.g., lake chains). Finally, total organic carbon (TOC) was used as a surrogate measure of the importance of allochthonous input from the boreal catchments. The sites used in this study are often natural brownwater systems, with high contents of humic substances.

We attempted to (1) identify and quantify possible sources of variation in surface water chemistry of boreal streams and lakes, (2) determine which environmental factors and which spatial scales are most important in determining the surface water chemistry of boreal streams and lakes, and (3) determine similarities/differences in the factors driving stream/lake water chemistry.

\section{Methods}

\section{Study Site}

The data set used in this study consists of 390 streams and 361 lakes sampled as part of the Swedish national stream and lake survey in autumn 2000 (Johnson and Goedkoop 2000; Wilander and others 2003) (Fig. 1). A number of factors suggested that this dataset was sufficiently robust for examining among-site similarities/dissimilarities in surface water chemistry of boreal streams and lakes. Firstly, streams and lakes were selected randomly; thus, the samples should be representative of the population of streams and lakes sampled. In selecting lakes, only lakes with surface areas $>4$ ha were included, and two size classes were used for stratifying stream sites (catchment area classes of 15 to 50 and 50 to $250 \mathrm{~km}^{2}$ ). Because we were interested in obtaining a depth-integrated measure of surface water chemistry, lakes were sampled during autumn turnover. Hence, sampling started in the northernmost parts of the country and progressed southwards. A more detailed description of stream and lake selection is given in Wilander and others (2003). In this study, we were interested in understanding the effects of local and regional-scale variables on the expected natural variability of selected water chemistry variables. Thus, sites deemed to be affected by liming, acidification (lakes: critical load exceedence of $\mathrm{S}$ and $\mathrm{N}>0$; Rapp and others (2002)) and agriculture/silviculture (catchments with more than $25 \%$ defined as arable and affected by clear-cutting, respectively) were not included in this dataset.

The streams and lakes can be classified as relatively small (mean stream width $=5 \mathrm{~m}$; mean lake area $=$ $3.27 \mathrm{~km}^{2}$ ), nutrient poor, ranging from clear to brownwater ecosystems (mean stream abs $420 \mathrm{~nm}=0.188$; mean lake abs $420 \mathrm{~nm}=0.149)$. The streams and lakes were distributed fairly evenly across the country. Streams were generally situated at a somewhat lower altitude than lakes $(201 \mathrm{~m}$ a.s.l. for streams and mean altitude $=$ $331 \mathrm{~m}$ a.s.l. for lakes). The catchment area of streams 


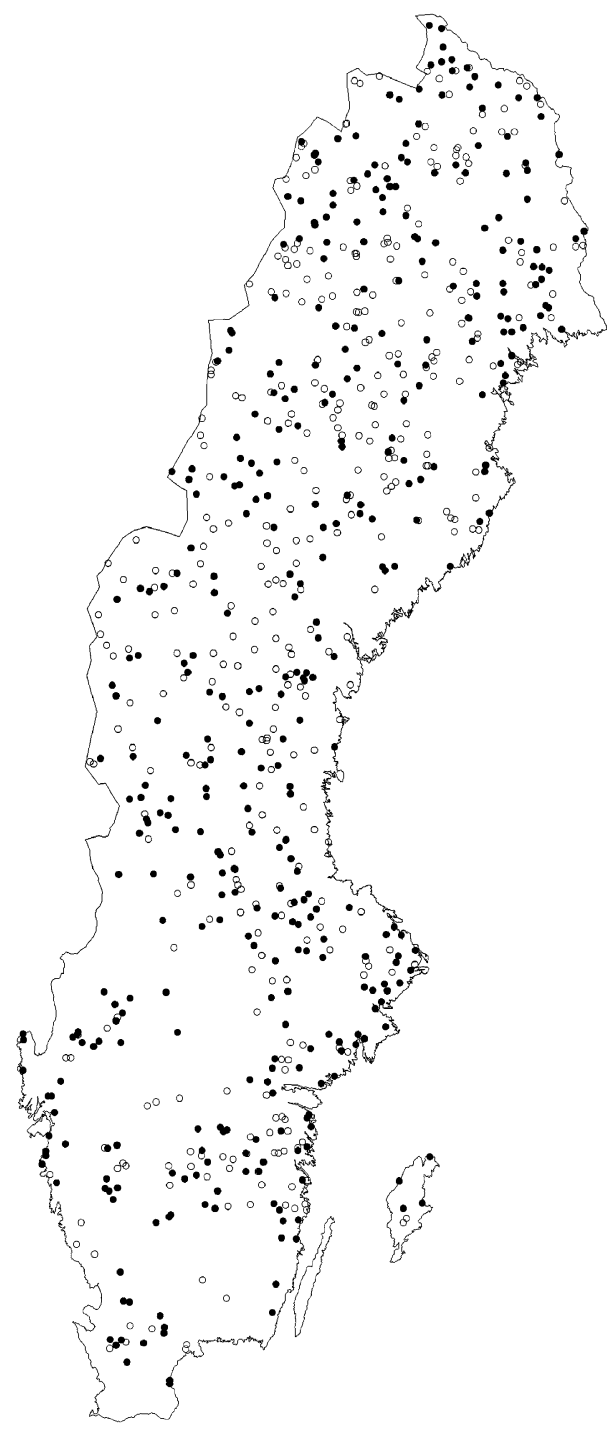

Fig. 1 Location of the 361 lakes and 390 streams used to assess the influence of geographic position, and regional and local scale factors on surface water chemistry

was also smaller (mean catchment area $=64 \mathrm{~km}^{2}$ ) than that of lakes $\left(257 \mathrm{~km}^{2}\right)$, because streams with catchments $>250 \mathrm{~km}^{2}$ were not included in the national stream survey.

\section{Water Chemistry}

A single, midstream or midlake (approximately $0.5 \mathrm{~m}$ depth) water sample was collected in autumn 2000. All water chemistry analyses were done by the SWEDAC (Swedish Board for Accreditation and Conformity Assessment) certified laboratory at the Department of Environmental Assessment, Swedish University of Agricultural Sciences following international (ISO) or European (EN) standards when available. ANC is a measure of the buffering ability of lakes and streams against strong acid inputs. This metric was chosen because it includes humic substances and compensates for their natural variation, i.e., the effect of acid deposition is more pronounced than in other acidification indicators such as $\mathrm{pH}$ or sulfate concentration.

Independent Variables

During sampling, sites were classified according to (aquatic) substratum particle size and vegetation; six substrate classes (ranging from silt/clay to block), two classes of detritus (coarse and fine), and 10 classes of riparian land use and vegetation were classified using four categories as: $0 \%,<5 \%, 5-50 \%$, and $>50 \%$ coverage (Table 1). For streams, 50-m reaches (sampling site) of relatively homogeneous substratum were chosen, and the riparian vegetation designated at a 5-m-wide zone on both sides of the sampling site was classified as above. For lakes, 10-m long and 5-m wide littoral areas of relatively homogeneous substratum were chosen and riparian vegetation, designated at a 50-m long and 5-m wide shoreline zone, was classified as above.

Catchments were classified as percentage land use/ vegetation cover according to the same land use categories used for riparian zones. Hence, catchment land use/cover ranged from $0 \%$ (all classes) to $100 \%$. Thereby, maximum urban areas in catchments were $10.2 \%$ (lakes) and $26.3 \%$ (streams), forested areas covered $99.8 \%$ in both lake and stream catchments, and alpine treeless cover was very high with $99.7 \%$ (lakes) and $99.9 \%$ (streams). Glacier areas comprised only $2.3 \%$ of total lake catchment areas, but covered $26.6 \%$ of stream catchments; other open freshwater bodies in the catchment comprised $19.4 \%$ of lake and $28.9 \%$ of stream catchments. Maximum marsh or mire land cover was $82.9 \%$ for lake and $67.4 \%$ for stream catchments, whereas pasture comprised $18.1 \%$ (lakes) and $14.2 \%$ (streams). Maximum alpine forested area cover was higher in lake $(98.7 \%)$ than in stream catchments $(65.6 \%)$, and maximum arable land covered $24.4 \%$ of lake and $24.6 \%$ of stream catchments.

Ecoregion delineation of Sweden was obtained from the Nordic Council of Ministers (1984). The ecoregions range from the nemoral region in the south to the arctic/ alpine complex in the north. The nemoral region is characterized by deciduous forest, mean annual temperatures $>6^{\circ} \mathrm{C}$, and a relatively long growth period (180-210 d). In contrast, the arctic/alpine complex in the north is characterized by relatively low mean annual temperatures $\left(<2^{\circ} \mathrm{C}\right)$ and short growth periods $(<140 \mathrm{~d})$. Geographic position descriptors (longitude, latitude, altitude), ecoregion delineation, discharge, deposition variables, land use/ vegetation cover descriptors, physical properties (stream width, lake area) as well as aquatic substrate descriptors 
Table 1 Dependent and independent variables used in RDA

\begin{tabular}{|c|c|c|c|}
\hline Variable & Unit & Lakes $(N=361)$ & Streams $(N=391)$ \\
\hline \multicolumn{4}{|l|}{ a) Dependent } \\
\hline Acid neutralizing capacity (ANC) & meq $1^{-1}$ & $3.36(0.09-0.74)$ & $0.51(0.15-0.99)$ \\
\hline Total phosphorus (TP) & $\mu \mathrm{g} 1^{-1}$ & $13.17(2-28)$ & $27.42(2-67)$ \\
\hline Total organic carbon (TOC) & $\mathrm{mg} 1^{-1}$ & $9.13(2.02-16.6)$ & $10.57(2.2-21.08)$ \\
\hline \multicolumn{2}{|l|}{ b) Independent } & Explained variability & \\
\hline \multicolumn{2}{|l|}{ Geographic position } & Lakes & Streams \\
\hline Latitude & Decimal degrees & & \\
\hline Altitude & m a.s.l. & $18.5 \%^{(2)}$ & $2.7 \%^{(3)}$ \\
\hline Ecoregions ${ }^{*}$ & Dummy variable & & \\
\hline Arctic/alpine & Dummy variable & & \\
\hline Northern boreal & Dummy variable & & \\
\hline Southern boreal & Dummy variable & & \\
\hline Boreonemoral & Dummy variable & & \\
\hline Nemoral & Dummy variable & & \\
\hline \multicolumn{4}{|l|}{ Regional factors } \\
\hline Mean annual discharge (Q) & $\mathrm{m}^{3} \mathrm{~s}^{-1}$ & & $1.3 \%(5)$ \\
\hline \multicolumn{4}{|l|}{ Wet \& Dry $\mathrm{NH}_{\mathrm{x}}$ deposition } \\
\hline \multicolumn{4}{|l|}{ Wet \& dry non-seasalt $\mathrm{Mg}$ deposition } \\
\hline \multicolumn{4}{|l|}{ Catchment land use/cover } \\
\hline Urban areas & $\%$ & & \\
\hline Forested areas & $\%$ & & \\
\hline Alpine treeless land cover & $\%$ & $55.4 \%^{(1)}$ & $17.3 \%{ }^{(2)}$ \\
\hline Glacier & $\%$ & & \\
\hline Open freshwater bodies & $\%$ & & \\
\hline Marsh/mires & $\%$ & & \\
\hline Arable land & $\%$ & $4.6 \%^{(3)}$ & $68 \%{ }^{(1)}$ \\
\hline Pasture & $\%$ & & \\
\hline Alpine forested areas & $\%$ & & \\
\hline \multicolumn{4}{|l|}{ Local factors } \\
\hline \multicolumn{4}{|l|}{ Physical properties of sample site } \\
\hline Stream width $\mathrm{m}$ & $\mathrm{M}$ & & $2.7 \%^{(4)}$ \\
\hline Lake area & $\mathrm{km}^{2}$ & $1.5 \%(5)$ & \\
\hline Water temperature & ${ }^{\circ} \mathrm{C}$ & & \\
\hline Aquatic substrate ${ }^{* *}$ & Classified $0-3$ & & \\
\hline Boulder $(>250 \mathrm{~mm})$ & Classified 0-3 & & \\
\hline Block (200-250 mm) & Classified $0-3$ & & \\
\hline Cobble (60-200 mm) & Classified 0-3 & & \\
\hline Pebble $(20-60 \mathrm{~mm})$ & Classified 0-3 & & \\
\hline Silt/clay $(0.02 \mathrm{~mm})$ & Classified 0-3 & & \\
\hline Coarse detritus & Classified 0-3 & & \\
\hline Floating leaved vegetation & Classified 0-3 & $4.6 \%(4)$ & \\
\hline Fine leaved submerged vegetation & Classified 0-3 & & \\
\hline Periphyton & Classified 0-3 & & \\
\hline Fine dead wood & Classified 0-3 & & \\
\hline \multicolumn{4}{|l|}{ Riparian land use/cover } \\
\hline Deciduous forest & Classified 0-3 & & \\
\hline Heath & Classified 0-3 & & \\
\hline Arable land & Classified 0-3 & & \\
\hline Alpine & Classified 0-3 & & \\
\hline Pasture & Classified 0-3 & & \\
\hline Mire & Classified 0-3 & & \\
\hline Canopy cover & Classified 0-3 & & \\
\hline
\end{tabular}

a) Chemistry variables $(n=3)$ with mean values and 10th and 90th percentiles in parentheses. $b)$ Environmental variables $(n=38)$, divided into three subsets, included in the analyses. Also shown are the first five variables (explained variability in \%) that could best explain the variability in ANC, TP, and TOC, using RDA and stepwise forward selection with the order of selection shown in parentheses. Note: the middle boreal ecoregion was insignificant in the Monte Carlo permutation test and excluded from the analysis

${ }^{*}$ Six major ecoregions according to the Nordic Council of Ministers (1984)

${ }^{* *}$ Classified as percent coverage where no coverage $0=0 \%$, very low coverage $1=<5 \%$, medium coverage $2=5-50 \%$, high coverage $3=>50 \%$ 


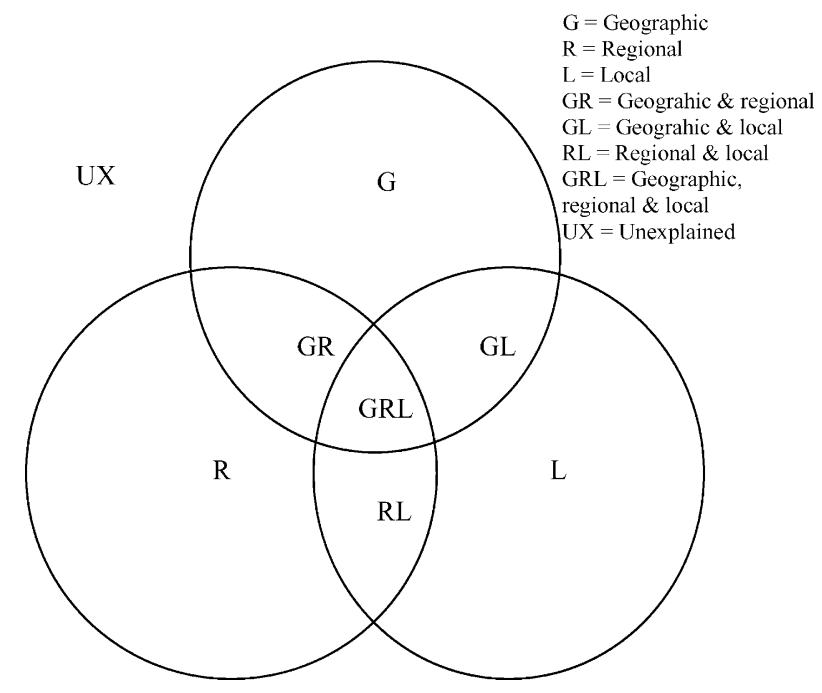

Fig. 2 Venn diagram (hypothetical model) showing the unique variation, the partial common variation, and the common variation of the three subsets $\mathrm{G}, \mathrm{R}$, and $\mathrm{L}$ representing the environmental data

resulted in a dataset of 60 environmental (independent) variables.

\section{Statistical Analyses}

First, detrended correspondence analyses were conducted to obtain the gradient length of both the stream and lake chemistry data. Because the gradient lengths were in both cases $\leq 1.5 \mathrm{SD}$, the linear method redundancy analysis (RDA) was used to study the effects of environmental variables representing geographic position and regional- and localscale factors on stream and lake water chemistry. Moreover, preliminary analyses of water chemistry (total phosphorus concentration) and catchment land use (\% agriculture) did not reveal any step changes between the northern and southern regions. RDA was performed on a correlation matrix and is a form of direct gradient analysis (like Principal Components Analysis). In a first step in RDA, the entire set of 60 environmental variables was tested to determine the significance of individual variables using a Monte Carlo permutation test (with 999 unrestricted permutations). Variables that were not significantly correlated with the three water chemistry variables or that were found to co-vary with other environmental variables (i.e., variance inflation factors $>100)$ were removed $(\mathrm{n}=22)$ from the data set.

\section{Variance Partitioning}

The remaining 38 explanatory variables were grouped into three subsets to yield ecologically interpretable variance components as follows: (1) variables describing the geographic position $(\mathrm{G})$ of the water body, (2) regional scale (R), and (3) local scale (L) variables (Fig. 2, Table 2).
Table 2 The procedure of variation partitioning of water chemistry $(n=3)$ in streams $(n=390)$ and lakes $(n=361)$ explained by three sets of environmental variables, geographic $(\mathrm{G})$, regional $(\mathrm{R})$, and local (L) in partial redundancy analysis (pRDA)

\begin{tabular}{lllll}
\hline Run & $\begin{array}{l}\text { Environmental } \\
\text { variable }\end{array}$ & Covariable & $\lambda_{\text {streams }}$ & $\lambda_{\text {lakes }}$ \\
\hline 1 & GRL & None & 0.751 & 0.651 \\
2 & Geo & R\&L & 0.018 & 0.037 \\
3 & R\&L & None & 0.733 & 0.614 \\
4 & R\&L & Geo & 0.173 & 0.184 \\
5 & Geo & None & 0.578 & 0.467 \\
6 & Reg & G\&L & 0.099 & 0.078 \\
7 & G\&L & None & 0.652 & 0.573 \\
8 & G\&L & Reg & 0.055 & 0.116 \\
9 & Reg & None & 0.696 & 0.535 \\
10 & Local & G\&R & 0.029 & 0.058 \\
11 & G\&R & None & 0.721 & 0.593 \\
12 & G\&R & Local & 0.270 & 0.221 \\
13 & Local & None & 0.480 & 0.430 \\
\hline
\end{tabular}

${ }^{\mathrm{a}} \lambda=$ computed eigenvalue in RDA. These numbers are used to calculate the explanatory power of each component (see Table 3)

The variation partitioning technique used has been previously described by Borcard and others (1992) and hence we will not go into detail here. In brief, the procedure allows for the variance in the explanatory data set to be partitioned into different variable components through the use of covariables (i.e., variables whose influence is partialled out of the analysis). Initially, this technique was used to partition variation in ecological data sets into environmental and spatial components (e.g., Økland and Eilertsen 1994) and has been extended by incorporating three sets of explanatory variables (e.g., Anderson and Gribble 1998).

The total variance explained and the unique contributions of each subset and their joint effects were obtained by the following: (1) RDA was run with all three subsets as environmental variables and no covariables to obtain a measure of the total variance, (2) partial RDA was run with one of the three subsets as environmental variables and no covariables, and (3) partial RDA was run with one of the three subsets as environmental variables constrained by the remaining two groups as covariables and reverse. The third step was repeated three times and each subset was treated as environmental variables constrained by the remaining subsets as covariables. This procedure resulted in four runs of RDA for each subset combination or a total of 13 runs of RDA were done for the full set of analyses for each ecosystem (Table 2). With three subsets of environmental data, the total variation of water chemistry was then partitioned into seven components including covariance terms (Fig. 2, Table 3). The variation explained by these subsets is subtracted from the total variation (1.0 in case of RDA) to obtain the unexplained variation. 
Table 3 Calculation of explanatory power of each component in the variance partitioning model

\begin{tabular}{llll}
\hline Variation explained by factors & Abbreviation (see Figs. 2 \& 3) & Calculation (no. of run, Table 2) & $\lambda_{\text {streams }}$ \\
\hline Geographic & G & 2 & 0.018 \\
Regional & R & 6 & 0.037 \\
Local & L & 10 & 0.078 \\
Geographic \& regional & GR & $12-6-2$ & 0.059 \\
Geographic \& local & GL & $8-2-10$ & 0.029 \\
Regional \& local & RL & $4-6-10$ & 0.153 \\
Geographic, regional \& local & GRL & $7-8-(12-6-2)-(4-6-10)$ & 0.008 \\
Total explained & TotX & 1 & 0.021 \\
Unexplained & UX & TotV-TotX & 0.045 \\
Total variance & TotV & & 0.399 \\
\end{tabular}

${ }^{\mathrm{a}}$ Abbreviations refer to the legend in Fig. 2. The figures in the calculation column refer to the runs in Table 2

\section{Stepwise RDA}

Stepwise RDA with forward selection was performed with all 38 environmental variables as independent variables and the 3 water chemical variables (ANC; TP and TOC) as dependent variables to determine the best predictors (high $R^{2}$ values). In this procedure, selected variables are run as co-variables and subsequent variables (step 2 and on) need to explain a significant amount of the residual variance (tested by Monte Carlo permutation).

Redundancy analyses and partial RDA were done using CANOCO for Windows Version 4.5 (Ter Braak and Smilauer 1997-1998). Prior to all statistical analyses (RDA), chemical and deposition variables, stream width, lake area, and altitude were log-transformed and proportional catchment land use/vegetation cover variables were arcsine square-root transformed to achieve normal distribution (SAS).

\section{Results}

Variance decomposition using redundancy analysis showed that all independent variables combined explained more than $65 \%$ of the total variation in stream and lake surface water chemistry (Table 3). The amount of variation explained was somewhat higher for streams $\left(\lambda_{\text {streams }}=0.751\right)$ compared to lakes $\left(\lambda_{\text {lakes }}=0.651\right)$. The largest proportion of variance was explained by the interaction between all three scale factors (Fig. 3).

Both stream and lake surface water chemistry was more influenced by regional-scale factors than either by geographic position or local-scale factors. However, the unique variance explained by geographic position, regional- or local-scale variables was low $(<10 \%)$ (Fig. 3). For streams, the unique variance explained by regionallevel variables $(9.9 \%)$ was substantially higher than that explained by local-scale variables $(2.9 \%)$ or geographic position $(1.8 \%)$. Similarly, for lakes the unique variance explained by regional-scale variables $(7.8 \%)$ was higher

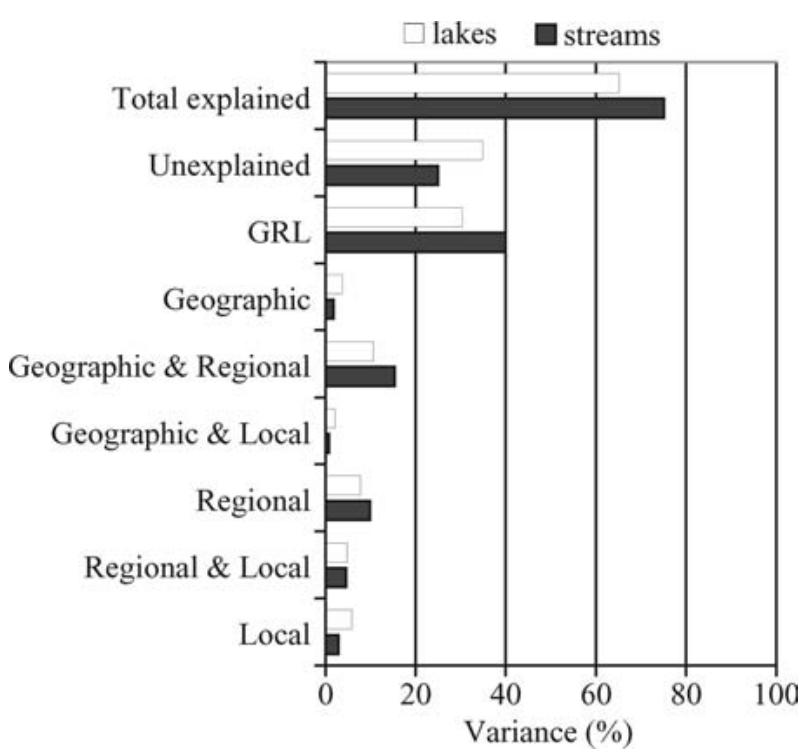

Fig. 3 Sources of variation in lake and stream water chemistry, respectively. Column labels indicate the variation (\%) in acid neutralizing capacity, total phosphorus, and total organic carbon accounted for by each subset and their combinations

than that explained by local-scale variables $(5.8 \%)$ and that explained by geographic position (3.8\%). Geographic position and regional-scale factors $(\mathrm{G} \& \mathrm{R})$ were better predictors of surface water chemistry than regional and local (R\&L) or geographic position and local (G\&L) factors. The strongest interaction was found between geographic position and regional-scale variables. For streams, the interaction between geographic position and regional-scale variables $(\mathrm{G} \& \mathrm{R})$ explained $15.3 \%$ of the variance in stream chemistry. For lakes, the G\&R interaction explained $10.6 \%$ of the variance in lake chemistry. The relation between geographic position and local-scale variables was much weaker, in particular for streams. The G\&L interaction explained $0.8 \%$ of the variance in stream and $2.1 \%$ of the variance in lake chemistry. The amount of variance explained by the interaction between 
Fig. 4 RDA biplot of environmental factors and ANC, $\mathrm{TP}$, and TOC of (A) streams and (B) lakes. 1 = riparian pasture cover; 2 = floating leaved vegetation; 3 = riparian deciduous forest cover; $4=$ riparian alpine cover; $5=$ riparian heath cover; $6=$ boulder; $7=$ block; $8=$ pebble; $9=$ periphyton; $10=$ cobble; 11 = fine leaved submerged vegetation; 12 = water temperature; $13=$ wet $\&$ dry non-sea salt $\mathrm{Mg}$ deposition; 14 = riparian arable cover (streams), alpine forest (lakes); eco1 $=$ arctic/alpine ecoregion; eco2 = northern boreal ecoregion; eco4 = southern boreal ecoregion; eco5 = boreonemoral ecoregion; = nemoral ecoregion; $\mathrm{WDNH}_{\mathrm{x}}=$ Wet \& Dry $\mathrm{NH}_{\mathrm{x}}$ deposition; c_detritus = coarse detritus; f_detritus = fine detritus; FWD $=$ fine wooded debris (substrate); $\mathrm{Q}=$ annual mean discharge

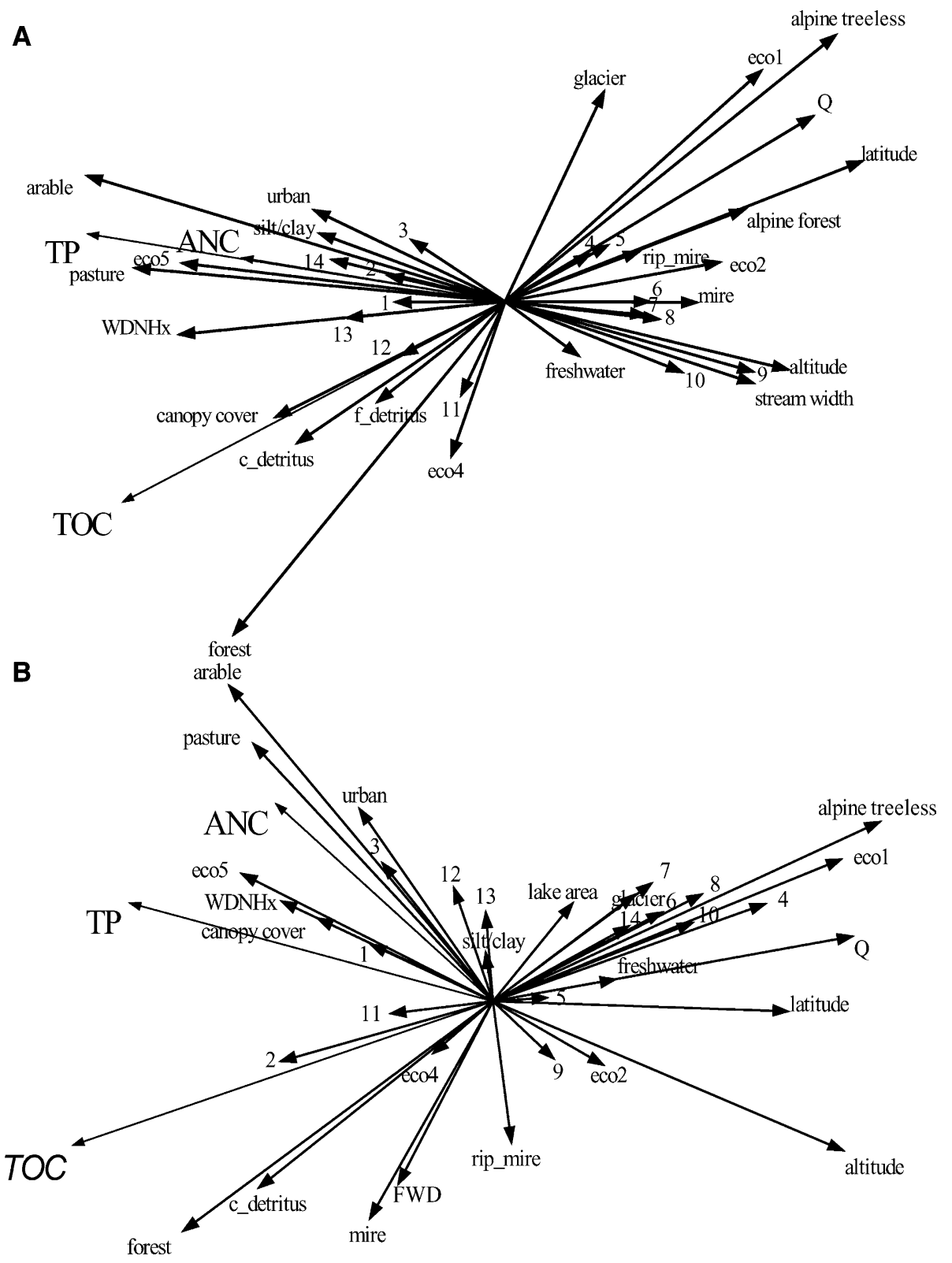

regional- and local-scale variables was $4.5 \%$ for streams and $4.8 \%$ for lakes.

Ordination of stream chemistry and environmental variables showed that the primary RDA axis represented a latitudinal gradient (Fig. 4a). Eigenvalues for the first and second RDA axes were 0.685 and 0.056 , respectively. Streams situated in alpine forested or alpine treeless catchments were placed on the right side of the ordination, whereas lowland streams situated in pasture and arable landscape in the south (e.g., boreonemoral ecoregion, eco5) with high wet and dry deposition of $\mathrm{NH}_{\mathrm{x}}$ (WDNHx) were placed to left. ANC and TP were strongly associated with pasture and arable land use and high WDNHx. TOC concentration was positively correlated with forested catchments and habitats with high amounts of coarse detrital matter and negatively correlated with mean annual discharge (Q) and, like lake-TOC, unrelated to arctic/mountainous characteristics. The second RDA axis was related to glacial land cover and whether the stream was located in the southern boreal ecoregion (eco4).

All three lake chemistry variables were negatively correlated with the first RDA axis (Fig. 4b). Eigenvalues for the first and second RDA axes were 0.599 and 0.056, respectively. The first RDA axis represented gradients in latitude and catchment/ecoregion. Lakes situated in alpine, treeless catchments at high latitude and altitude were situated to the right, whereas sites situated in forested catchments or catchments with pasture or arable land use were placed to the left in the ordination. Both ANC and TP were positively correlated with the amount of catchment 
classified as pasture and arable. Moreover, many of these lakes were situated in the boreonemoral ecoregion (eco5), with high wet and dry deposition of $\mathrm{NH}_{\mathrm{x}}$ (WDNHx). In contrast, lake water total organic carbon (TOC) was associated with forested catchments, with high amounts of coarse detrital matter (c_detritus). The second RDA axis represented gradients in the amount of catchment classified as mire (or bog), in particular the importance of local factors such as substrate type, water temperature, and riparian mire and fine wooded debris (FWD).

Stepwise RDA of stream and lake chemistry as dependent variables and the "single" variables of geographic position and regional and local environmental variables showed that all variables accounted for $65 \%$ (lakes) and $75 \%$ (streams) of the total variance. The amount of alpine treeless areas in the catchment was the single most important predictor of lake water chemistry (explaining $55.4 \%$ of the explained variance). The second variable selected was altitude $(18.5 \%$, i.e., the amount of residual variance explained after running the first variable selected, " 'alpine treeless areas in the catchment,', as a covariable), followed by the amount of arable land in the catchment $(4.6 \%)$, percent coverage of floating leaved vegetation in the littoral $(4.6 \%)$, and lake surface area $(1.5 \%)$. For streams, the five best single predictors of water chemistry were the amount of arable land in the catchment $(68 \%)$, followed by the amount of alpine treeless areas in the catchment, altitude $(2.7 \%)$, stream width $(2.7 \%)$, and mean annual discharge Q (1.3\%).

\section{Discussion}

Lakes and streams are often perceived as structurally and functionally different ecosystems, and indeed major dissimilarities do exist regarding differences in water movement. For example, streams are characterized by unidirectional, turbulent flow and high flushing rates, whereas lake chemistry is more affected by the timing and frequency of turnover events (e.g., polymictic to dimictic mixing in boreal lakes). Furthermore, obvious differences in nutrient cycling and recycling are expected due to the relative importance of benthic vs. pelagic productivity (Essington and Carpenter 2000). The surface water chemistry of streams is considered to be tightly linked to catchment characteristics, with geomorphology determining soil type and availability of ions through weathering (e.g., Allan 1995). Lakes, on the other hand, have until recently been perceived as separate entities, more isolated than streams from the surrounding landscape (e.g., Kratz and others 1997; Soranno and others 1999; Riera and others 2000; Quinlan and others 2003). Clearly, terrestrialaquatic linkages are important predictors of surface water chemistry for both streams and lakes, but the strength of this interaction should vary with geologic and hydrologic settings. Thus, the major difference between the River Continuum Concept (Vannote and others 1980) and the concept of lake landscape position (Kratz and others 1997) probably lies in large differences in water residence times between streams and lakes. Given the differences in water movement, in particular flushing rates, one might expect that streams and lakes differ in the external drivers that affect water chemistry. Surprisingly, our findings do not support this conjecture; the major part of the variation in water chemistry in both streams and lakes was explained by all components (i.e., geographic position as well as regional- and local-scale variables), followed by the combination (or interaction) of geographic position and regional-scale factors. These findings support the premise that variability in surface water chemistry is driven by interactions between geographic position and regional factors. Our finding, however, that regional factors alone accounted for a large part of variation in $\mathrm{ANC}$, TP, and TOC indicates the pivotal role that catchment land use/ cover plays in determining surface water chemistry.

The finding that the surface water chemistry of streams and lakes could be partly predicted by regional-scale variables, in particular catchment land use (e.g., arable) agrees with the findings of several earlier studies (e.g., Schonter and Novotny 1993; Allan and others 1997). Johnson and others (1997) showed, for example, that urban land use and rowcrop agriculture were important factors in explaining variability in stream water chemistry. Similarly, Hunsaker and Levine (1995) were able to explain more than $40 \%$ of the variance in total nitrogen using landscape metrics. In our study, we were interested in analyzing "natural", variability, so we removed sites judged to be affected by agriculture (i.e., sites with $>25 \%$ of their catchments classified as arable were not included). Hence, our finding that the amount of arable land in a catchment explained nearly $70 \%$ of the variability in stream water chemistry was not expected using these data, and implies that even a small-scale agricultural land use within a catchment may affect phosphorus concentration. The importance of a riparian zone has been proposed to be less important in explaining among-site differences in heavily managed catchments (Omernik and others 1981). These authors suggested that the total amount of agriculture and forest in a catchment are more important predictors of water chemistry than the vegetation composition of the riparian zone. Our finding that less than $6 \%$ of the variation in surface water chemistry was explained by local factors alone (such as the presence of a riparian zone) supports this conclusion. Furthermore, in contrast to regional-scale factors, only a small amount of the variation was "hidden" in joint effects or interaction terms between regional and local 
$(<8 \%)$ and between geographic and local $(<3 \%)$ variables. Hence, other factors not considered here, such as where the land use is located in the catchment and in relation to the water body, presumably need to be considered. Indeed, studies of small scale or local factors have been shown to be important in modifying larger scale effects, e.g., several studies have shown the ameliorative influence of a vegetated riparian zone (e.g., Cooper 1990; Osborne and Kovacic 1993).

Redundancy analysis showed that the variability in both stream and lake water chemistry was explained by the similar regional- and local-scale variables. For example, as discussed above, the proportion of arable land use in the catchments was a strong predictor of stream water chemistry $(68 \%)$, followed by alpine, treeless land cover $(17.3 \%)$. For lake water chemistry, the amount of alpine, treeless land cover was a good predictor (55.4\%), followed by altitude $(18.5 \%)$ and catchment arable land use (4.6\%). Clearly, several of the variables in different "local" and "regional" components covary. For instance, the amount of alpine treeless land cover in the region/catchment and stream width are presumably correlated with altitude. However, as demonstrated here, regional factors were better predictors of stream and lake water chemistry and thus contribute largely to the explanatory power of the covariation components.

All three water chemistry variables were strongly correlated with variables representing a latitudinal gradient; for example, sites in the south are more well buffered and nutrient rich compared to sites in the north. This distinct north-south gradient in water chemistry was not unexpected, but can be easily explained by major landscape-level differences between the northern and southern parts of the country. For instance, the legacy of historical processes on present-day distribution patterns of vegetation is clearly visible in Sweden. At approximately $60^{\circ} \mathrm{N}$ latitude, a marked difference in vegetation occurs, and this ecotone (limes norrlandicus) basically delineates the transition of broad-leaved (e.g., English oak and elm) and coniferous mixed (e.g., Scots pine and spruce) forests in the south from the boreal pine and spruce forests in the north (Nordic Council of Ministers 1984). In addition, the limes norrlandicus ecotone is also correlated with the highest postglacial coastline or the highest level the sea reached after the last ice age and below which fluvial sediments have been deposited. Hence, these two landscape-scale discontinuities in vegetation and soil type can have profound importance for surface water chemistry. Finally, broad-scale climatic differences also exist between the northern and southern parts of the country, which are manifested in differences in discharge regimes. For example, streams in the south are dominated by autumn and winter rains, whereas streams in the north are dominated by snowmelt-driven peaks in runoff during spring (Anonymous 1979).

Given the profound differences in climate, geomorphology, and vegetation between the northern and southern parts of the country, we anticipated discernible differences in the factors driving surface water chemistry. Indeed, the finding that landscape position is important in explaining variability in surface water chemistry has been shown in previous studies (e.g., Johnson 1999), and supports the use of ecoregions to partition natural variability. Ecoregions have been suggested as appropriate ecological units for classification because they are generally perceived as being relatively homogeneous, having similar climate, geology, and other environmental characteristics (Wright and others 1998), and hence are considered as relatively good predictors of spatial patterns of surface water chemistry (e.g., Landers and others 1988; Larsen and others 1988). However, to be an appropriate classification tool, an ecoregion should minimize within and maximize among region variability, and, ideally, knowledge of how both natural and human-induced variability affect ecosystem processes should be known in order to fully assess the adequacy of ecoregions for partitioning natural variability. For example, it is well known that catchment management practices can have profound effects on surface water quality. For instance, whether a catchment is forested (promotes infiltration, high transpiration, and reduces runoff), clear-cut (results in lower infiltration and transpiration and increased runoff), or reforested may singly or in concert affect the water chemistry of aquatic ecosystems (Foster and others 2003).

The results of this study showed the importance of interactions between variables acting on multiple spatial scales on among-lake and stream water chemistry. Somewhat surprising was the finding that the major drivers were similar between lakes and streams, despite the obvious differences in ecosystem types. For instance, in streams nutrients are spiralling downstream, whereas in lakes, nutrient retention is relatively high, depending on lake size and morphometry. Obviously, the chemical composition of a surface water body is a product of a series of mechanisms and processes acting along a scale continuum, i.e., from broad (geographic) to small (local) scales. Moreover, the environmental characteristics of a specific habitat are not random, but are considered to be controlled by macro-scale geomorphic patterns (Frissell and others 1986). Building on this premise, a conceptual framework has been developed where the aquatic (stream) organism assemblage at a site can be seen as a product of a series of filters (e.g., from continental to microhabitat), with each species occurring at a site having passed through these filters (e.g., Tonn and others 1990; Poff 1997). Similarly, surface water chemistry of a particular site is also constrained to some extent by a 
number of environmental filters. Small-scale systems develop within the constraints set by broad-scale systems of which they are part, and likewise local-scale processes and conditions are generated by broad-scale, geographic patterns and conditions.

The idiosyncrasies of both ecosystems might be suppressed by the effects of large-scale factors. Geographic position functions as a template determining both regional and local factors. At the catchment level, geology controls soil type, weathering determines ion concentrations (and buffering capacity), and climate determines vegetation type (and land use). However, changes in land use (e.g., afforestation of arable to urban) and/or vegetation cover (e.g., deforestation or afforestation of arable land) are sources of catchment variation that might generate high amounts of variability or noise, making it difficult to tease apart components of natural variation from the effects of anthropogenic impact on surface water chemistry. This inherent catchment variation is probably responsible for the large amount of variation explained by regional factors, which may hide the effects of individual features of lakes and streams appearing similar in their response to environmental factors and influences. However, another caveat in addressing issues of "scale-effects" is that the spatial resolution at which observations are made can confound interpretation of scale-related processes (e.g., Minshall 1988; Manel and others 2000). For example, environmental variables such as nutrient concentrations and hydrology are more influenced by regional-scale processes, whereas other variables such as in-stream vegetation cover are more influenced by local control mechanisms (e.g., Allan and others 1997). Our findings of the importance of interactions between geographic position and regional- and local-scale variables support this conclusion.

Acknowledgments We thank the many people who assisted in the planning, sampling, and processing of the large number of samples collected in the 2000 national lake and stream survey.

\section{References}

Allan J. D. 1995. Stream ecology. Structure and function of running waters. Chapman and Hall, London

Allan J. D., D. L. Erickson, J. Fay. 1997. The influence of catchment land use on stream integrity across multiple spatial scales. Freshwater Biology 37:149-161

Anderson M. J., N. A. Gribble. 1998. Partitioning the variation among spatial, temporal and environmental components in a multivariate data set. Australian Journal of Ecology 23:158-167

Anonymous. 1979. Streamflow records of Sweden. The Swedish Meteorological and Hydrological Institute. Stockholm pp. 403 (in Swedish).

Borcard D., P. Legendre, P. Drapeau. 1992. Partialling out the spatial component of ecological variation. Ecology 73:1045-1055
Cooper A. B. 1990. Nitrate depletion in the riparian zone and stream channel of a small headwater catchment. Hydrobiologia 202:1326

Essington T. E., S. R. Carpenter. 2000. Nutrient cycling in lakes and streams: Insights from a comparative analysis. Ecosystems 3:131-143

Foster D., F. Swanson, J. Aber, I. Burke, N. Brokaw, D. Tilman, A. Knapp. 2003. The importance of land-use legacies to ecology and conservation. Bioscience 53:77-88

Frissell C. A., W. J. Liss, C. E. Warren, M. D. Hurley. 1986. A hierarchical framework for stream habitat classification-viewing streams in a watershed context. Environmental Management 10:199-214

Hornung M., K. R. Bull, M. Cresser, J. Ullyett, J. R. Hall, S. Langan, P. J. Loveland, M. J. Wilson. 1995. The sensitivity of surface waters of Great Britain to acidification predicted from catchment characteristics. Environmental Pollution 87:207-214

Hunsaker C. T., D. A. Levine. 1995. Hierarchical approaches to the study of water quality in rivers. Bioscience 45:193-203

Hynes H. B. N. 1975. The stream and its valley. Verhandlungen der Internationalen Vereinigung für Theoretische und Angewandte Limnologie 19:1-15

Johnson L. B., C. Richards, G. E. Host, J. W. Arthur. 1997. Landscape influences on water chemistry in Midwestern stream ecosystems. Freshwater Biology 37:193-208

Johnson R. K. 1999. Regional representativeness of Swedish reference lakes. Environmental Management 23:115-124

Johnson R. K., W. Goedkoop. 2000. The 1995 national survey of Swedish lakes and streams: assessment of ecological status using macroinvertebrates. In J. F. Wright D. W. Sutcliffe, M.T. Furse (eds), Assessing the biological quality of freshwaters. RIVPACS and other techniques. Freshwater Biological Association, Ambleside, UK. pp 9-240

Kratz T. K., K. E. Webster, C. J. Bowser, J. J. Magnuson, B. J. Benson. 1997. The influence of landscape position on lakes in northern Wisconsin. Freshwater Biology 37:209-217

Landers D. H., J. M. Eilers, D. F. Brakke, P. E. Kellar. 1988. Characteristics of acidic lakes in the eastern United States. Verhandlungen der Internationalen Vereinigung für Theoretische und Angewandte Limnologie 23:152-162

Larsen D. P., D. R. Dudley, R. M. Hughes. 1988. A regional approach for assessing attainable surface-water quality-an Ohio case-study. Journal of Soil and Water Conservation 43:171176

Manel S., S. T. Buckton, S. J. Ormerod. 2000. Testing large-scale hypotheses using surveys: the effects of land use on the habitats, invertebrates and birds of Himalayan rivers. Journal of Applied Ecology 37:756-770

Minshall G. W. 1988. Stream ecosystem theory-a global perspective. Journal of the North American Benthological Society 7:263-288

Naumann E. 1932. Grundzüge der regionalen Limnologie. Die Binnengewässer 11:176

Nordic Council of Ministers. 1984. Naturgeografisk regionindelning av Norden. Nordiska ministerrådet 1984, Oslo, Norway (in Swedish)

Økland R. H., O. Eilertsen. 1994. Canonical correspondence-analysis with variation partitioning - some comments and an application. Journal of Vegetation Science 5:117-126

Omernik J. M., A. R. Abernathy, L. M. Male. 1981. Stream nutrient levels and proximity of agricultural and forest land to streams: some relationships. Journal of Soil and Water Conservation 36:227-231

Osborne L. L., D. A. Kovacic. 1993. Riparian vegetated buffer strips in water-quality restoration and stream management. Freshwater Biology 29:243-258 
Osborne L. L., M. J. Wiley. 1988. Empirical relationships between land-use cover and stream water-quality in an agricultural watershed. Journal of Environmental Management 26:9-27

Poff N. L. 1997. Landscape filters and species traits: Towards mechanistic understanding and prediction in stream ecology. Journal of the North American Benthological Society 16:391-409

Quinlan R., A. M. Paterson, R. I. Hall, P. J. Dillon, A. N. Wilkinson, B. F. Cumming, M. S. V. Douglas, J. P. Smol. 2003. A landscape approach to examining spatial patterns of limnological variables and long-term environmental change in a southern Canadian lake district. Freshwater Biology 48:1676-1697

Rapp L., A. Wilander U. Bertills. 2002. Kritisk belastning för försurning av sjöar. In U. Bertills G. R. Lövblad (eds), Kritisk belastning för svavel och kväve. Naturvårdsverket Rapport 5174, Stockholm (in Swedish). pp 81-106

Riera J. L., J. J. Magnuson, T. K. Kratz, K. E. Webster. 2000. A geomorphic template for the analysis of lake districts applied to the Northern Highland Lake District, Wisconsin, USA. Freshwater Biology 43:301-318

SAS. 1994. JMP-Statistics made visual, 3.1. SAS Institute Inc., Cary, North Carolina

Schonter R., V. Novotny. 1993. Predicting attainable water-quality using the ecoregional approach. Water Science and Technology 28:149-158

Soranno P. A., K. E. Webster, J. L. Riera, T. K. Kratz, J. S. Baron, P. A. Bukaveckas, G. W. Kling, D. S. White, N. Caine, R. C. Lathrop, P. R. Leavitt. 1999. Spatial variation among lakes within landscapes: Ecological organization along lake chains.
Ecosystems 2:395-410

Sverdrup H., P. Warfvinge, M. Rabenhorst, A. Janicki, R. Morgan, M. Bowman. 1992. Critical loads and steady-state chemistry for streams in the state of Maryland. Environmental Pollution 77:195-203

ter Braak C. J. F., P. Smilauer. 1997-1998. GLW-CPRO. Canoco for Windows, 4.0. Centre for Biometry Wageningen CPRO-DLO. Wageningen, The Netherlands

Thienemann A. 1925. Die Binnengewässer Mitteleuropas. Eine limnologische Einführung. Die Binnengewässer Band LE. Schweizerbart'sche Verlagsbuchhandlung pp. 255

Tonn W. M., J. J. Magnuson, M. Rask, J. Toivonen. 1990. Intercontinental comparison of small-lake fish assemblages-the balance between local and regional processes. American Naturalist 136:345-375

Vannote R. L., G. W. Minshall, K. W. Cummins, J. R. Sedell, C. E. Cushing. 1980. The river continuum concept. Canadian Journal of Fisheries and Aquatic Sciences 37:130-137

Wilander A., R. K. Johnson W. Goedkoop. 2003. Riksinventering 2000. En synoptisk studie av vattenkemi och bottenfauna i svenska sjöar och vattendrag. Rapport 2003:1. Institutionen för miljöanalys. Uppsala (in Swedish)

Vollenweider R. A. 1975. Input-output models, with special reference to the phosphorus loading concept in limnology. Schweizerische Zeitschrift für Hydrologie 37:53-84

Wright R. G., M. P. Murray, T. Merrill. 1998. Ecoregions as a level of ecological analysis. Biological Conservation 86:207213 